au bout d'une heure déjà le dégagement gazeux et la transformation chimique de la mannite commenceront. Il se forme de l'acide carbonique, de l'hydrogène, et la liqueur renferme de l'alcool, de l'acide lactique, de l'acide butyrique, tous les produits de la fermentation de la mannite.

Quant à l'acide butyrique, l'expérience prouve que la levûre lactique agit directement sur le lactate de chaux en donnant du carbonate de chaux et du butyrate de chaux. Mais l'action s'exerce d'abord sur le sucre, et tant qu'il y en a dans la liqueur, la levûre le fait fermenter de préférence à l'acide lactique.

Dans des communications très-prochaines, j'aurai l'honneur de présenter à l'Académie l'application des idées générales et des nouvelles méthodes d'expérimentation de ce travail à d'autres fermentations.

\title{
Report on the Lactic Acid Fermentation (Author's abstract)
}

\author{
Translation by Thomas D. Brock, Ph.D. \\ University of Wisconsin, Madison, Wisconsin
}

My work on the properties of the amyl alcohols and on the very remarkable crystallographic properties of their derivatives has led me to a study of the process of fermentation. Later I will have the honor to present to the Academy observations that show an unexpected relationship between fermentation and the molecular asymmetry of organic molecules found in nature.

The necessary materials for the preparation and production of lactic acid are well known to chemists. It is known that it is only necessary to take a solution of sugar and add chalk, which keeps the medium neutral, a nitrogenous material, such as casein, gluten, animal membranes, etc., in order to have the sugar transformed into lactic acid. But the explanation of this phenomenon is quite obscure, since the way in which the decomposable nitrogenous material acts is completely ignored. Its weight does not change significantly. It does not putrefy. Although it becomes modified and is continually in a marked state of change, it would be difficult to speak of what its composition is.

Careful studies up to the present time have not revealed the development of organized beings during the fermentation process. Those observers who have recognized such beings have always established at the same time that they were accidental and harmful to the fermentation process.

The facts appear therefore to be very favorable for the ideas of Mr. Liebig. In his eyes, the ferment is a substance that is highly alterable, which decomposes and in so doing induces the fermentation because of the alteration that it experiences itself, communicating this agitation to the molecular group of the fermentable material and in this way bringing about its decomposition. According to Mr. Liebig, this is the principal cause of all fermentations and the origin of the majority of contagious diseases. Each day his opinion receives more favor. ... ${ }^{1}$

I propose to establish in the first part of this work that, in the same way that there exists an alcoholic ferment, the yeast of beer, which is always found wherever sugar is decomposed into alcohol and carbon dioxide, there also exists a particular ferment, the lactic yeast, that is always present when sugar becomes converted into lactic acid. Furthermore, the decomposable nitrogenous material that is able to bring about the conversion of sugar into this acid is used as a convenient nutrient for the development of this ferment.

It is possible to observe in ordinary lactic acid fermentations, on top of the sediment of chalk and nitrogenous material, a gray substance which occurs at the surface of this deposit. Under microscopic examination it can be barely distinguished from the casein, disintegrating gluten, etc. so that nothing indicates that it may be a special material, nor that it has arisen during the fermentation. Nevertheless, it is this substance that plays the principal role in the fermentation. I will shortly reveal the method for its isolation and preparation in a state of purity.

I have extracted from beer yeast its soluble

${ }^{1}$ Ellipses denote material omitted from the original article. 
material by boiling it several times with 15 to 20 times its weight of water. This extract is filtered carefully. In this are dissolved 50 grams of sugar per liter, and some chalk is added. Then it is seeded with a trace of the gray material I mentioned above, and a good lactic acid fermentation is obtained of the usual sort. On the next day the fermentation is vigorous and regular. The liquid, which had been perfectly clear at the beginning, becomes turbid, the chalk gradually disappears, and at the same time a deposit is produced which increases continually and progressively at the same rate that the chalk disappears. In addition, all of the characteristics and symptoms of the well-known lactic acid fermentation are observed. In this experiment, it is possible to replace the yeast water with a decoction of any decomposable nitrogenous material, whether fresh or decomposed. Let us now see the nature of this substance that is correlated with all of the phenomena that are included under the words lactic acid fermentation. Its appearance is similar to that of the beer yeast when it is studied en masse and squeezed or pressed. Under the microscope it is seen to form tiny globules or small objects, which are very short, isolated or in groups of irregular masses. These globules are much smaller than those of beer yeast and move actively by Brownian movement. If washed with a large amount of water by decantation, then diluted into a solution of pure sugar, they immediately begin to make acid, but quite slowly since acid inhibits significantly their action on sugar. If chalk is added so that the medium is maintained at neutrality, the conversion of sugar is considerably accelerated, and even though only a small amount of material is acting, in less than an hour the production of gas is observed and the liquid contains large amounts of calcium lactate and butyrate. Only a small amount of this yeast is needed to convert a large amount of sugar. This fermentation is preferably carried out in the absence of air, since it is inhibited by plants or by parasitic infusoria.

Therefore, the lactic fermentation, like the ordinary alcoholic fermentation, is always correlated with the production of a nitrogenous material that has all the properties of an organized body of the mycodermal type, and is probably closely related to the yeast beer. But the difficulties of the subject are only half solved. There are many complications. Lactic acid is indeed the principal product of the fermentation that has been given its name, but it is far from the only product. Butyric acid, alcohol, mannitol, and a viscous material are always found accompanying the lactic acid. The proportions of these materials are highly variable. The circumstances with mannitol are especially mysterious, its proportions being subject to large variations. In addition, $\mathrm{M}$. Berthelot has shown that if sugar is replaced by mannitol in the lactic fermentation, mannitol is fermented to alcohol, lactic acid, and butyric acid. How is one to explain the formation of mannitol in the fermentation from sugar, when it should be destroyed at the same rate that it is produced? Let us examine carefully the chemical properties of this new yeast. I have stated that if it is washed well and placed in a pure sugar solution, it acidifies the liquid over a period of time. The conversion of sugar becomes gradually slower under these conditions, since the liquid becomes quite acidic. The liquid can be analyzed successfully only after the acid is neutralized with chalk and the excess sugar is destroyed by beer yeast. One then finds, if the liquid is evaporated, variable proportions of mannitol and viscous material. However, washed lactic yeast brings about the transformation of sugar into various products including always mannitol, only if the liquid is allowed to become quickly acid. If the same experiment is repeated with the precaution that an amount of chalk sufficient to continually neutralize the liquid is added, then neither the gum nor the mannitol are formed, or, perhaps more exactly, are quickly transformed further.

I reported above that $M$. Berthelot had shown that when mannitol is substituted for sugar in the lactic fermentation, this material is fermented. But it is simple to show that in this case, the fermentation of mannitol occurs when the lactic yeast develops and brings about its production. If a solution of pure mannitol is mixed with powdered chalk and fresh washed lactic yeast, within an hour gas appears and the chemical transformation of mannitol begins. Carbon dioxide and hydrogen are released, and the liquid contains alcohol, lactic acid, and butyric acid, all productions of the fermentation of mannitol.

Concerning butyric acid, experiments have shown that the lactic yeast acts directly upon calcium lactate and converts it into calcium carbonate and calcium butyrate. But sugar is acted upon first, and if it is present in the liquid, the yeast prefers to ferment it to lactic acid.

In a later communication I will have the honor of presenting to the Academy some general ideas and new methods of experimentation from work on other fermentations. 